\title{
Alarming spread of vancomycin resistant enterococci in Sweden since 2007
}

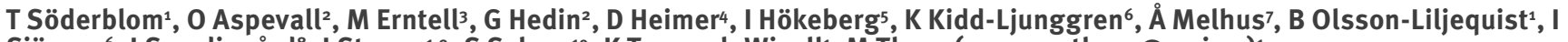
Sjögren ${ }^{6}$, S Smedjegård ${ }^{8}$, J Struwe ${ }^{1,9}$, S Sylvan ${ }^{10}$, K Tegmark-Wisell $^{1}$, M Thore (magnus.thore@smi.se) ${ }^{1}$

1. Swedish Institute for Infectious Disease Control (SMI), Solna, Sweden

2. Department of Clinical Microbiology and Infection Control, Karolinska University Hospital, Huddinge, Sweden

3. Department of Communicable Disease Control, County of Halland, Sweden

4. Department of Clinical Microbiology and Infection Control, County Hospital, Västerås, Sweden

5. Department of Communicable Disease Control, County of Stockholm, Sweden

6. Department of Clinical Microbiology and Infection Control, County Hospital, Halmstad, Sweden

7. Department of Clinical Microbiology and Infection Control, County Hospital, University Hospital, Uppsala, Sweden

8. Department of Communicable Disease Control, County of Västmanland, Sweden

9. Strama (Swedish Strategic Programme against Antibiotic Resistance), Solna, Sweden

10. Department of Communicable Disease Control, County of Uppsala, Sweden

Citation style for this article:

Söderblom T, Aspevall O, Erntell M, Hedin G, Heimer D, Hökeberg I, Kidd-Ljunggren K, Melhus Å, Olsson-Liljequist B, Sjögren I, Smedjegård J, Struwe J, Sylvan S, Tegmark-Wisell K, Thore M. Alarming spread of vancomycin resistant enterococci in Sweden since 2007. Euro Surveill. 2010;15(29):pii=19620. Available online: http://www.eurosurveillance.org/ViewArticle.aspx?Articleld=19620

Article published on 22 July 2010

The total number of persons infected or colonised with vancomycin-resistant enterococci mandatorily reported to the Swedish Institute for Infectious Disease Control increased dramatically during 2007 and 2008. During a period of twenty months from 1 July 2007 to 28 February 2009, a total of 760 cases were reported compared with 194 cases reported during the entire period from 2000 to 2006 . This rise was mainly attributed to a wide dissemination of vancomycin resistant enterococci which started in a number of hospitals in Stockholm in the autumn of 2007 and was followed by dissemination in various healthcare facilities (hospitals and homes for the elderly) in a further two Swedish counties in 2008. The majority of the cases (97\%) were acquired in Sweden and among these, healthcare-acquired $E$. faecium vanB dominated $(n=634)$. The majority of these isolates had identical or closely related pulsed-field gel electrophoresis patterns indicating clonal dissemination in the affected counties. The median minimum inhibitory concentration of vancomycin was $32 \mathrm{mg} / \mathrm{L}$ (ranging from 4 to $>128 \mathrm{mg} / \mathrm{L}$ ) and of teichoplanin $0.12 \mathrm{mg} / \mathrm{L}$ (ranging from 0.06 to $0.25 \mathrm{mg} / \mathrm{L}$ ). Particular emphasis was placed on countermeasures such as screening, contact tracing, cleaning procedures, education in accurate use of infection control practices as well as increasing awareness of hygiene among patients and visitors. With these measures the dissemination rate decreased substantially, but new infections with the $E$. faecium vanB strain were still detected.

\section{Introduction}

Enterococci may acquire various types of glycopeptide antibiotic resistance via van-associated genetic elements ( $\operatorname{van} A / B / D / E / G / L)$, of which $\operatorname{van} A$ and $\operatorname{van} B$ are the most prevalent in clinically relevant species $[1,2]$. Although vancomycin-resistant enterococci are seldom encountered in serious clinical infections, they occasionally cause invasive infections notably in immunocompromised hosts. Some of these infections, particularly those caused by Enterococcus faecium, are often difficult to treat since only few antimicrobial treatment options are available. Vancomycin-resistant $E$. faecium and $E$. faecalis (referred to as VRE throughout this paper) became mandatorily notifiable according to the Swedish Communicable Diseases Act in January 2000, and in 2004 an amendment concerning mandatory contact tracing was added.

According to studies performed in the late 1990 s the prevalence of VRE in Sweden was low in the community and in healthcare facilities [3,4] and remained so until the year 2006 with no more than 0.2-0.4 cases per 100,000 inhabitants and year [5]. Only a few minor healthcare -related outbreaks involving less than 20 patients each occurred during that period $[6,7]$. The prevalence of VRE among invasive $E$. faecium blood isolates in Sweden as reported to the European antimicrobial resistance surveillance system (EARSS; data representing more than $75 \%$ of the population) was generally less than $1 \%$ for most of the period from 2001 to 2006 [8]. This prevalence is clearly lower than reported from some other European countries $[8,9]$.

In the autumn of 2007 , there was a distinct increase in the number of persons infected or colonised with VRE as reported from various hospitals in Stockholm County. During 2008, this increase was also noted in two other counties, Västmanland and Halland, and the total number of reports increased more than 10 -fold between 2007 and 2008, showing little or no tendency to decrease during the first months of 2009. The aim of this study was to describe the epidemiology of the dissemination of VRE in the affected counties. 


\section{Methods}

National surveillance system for

vancomycin-resistant enterococci

In Sweden, contact tracing is performed whenever VRE is detected in a clinical sample. Furthermore, screening for VRE is recommended in all patients who have

\section{FIGURE 1}

County distribution of domestic cases with vancomycinresistant enterococci, Sweden, 1 July 2007-28 February $2009(n=738)$

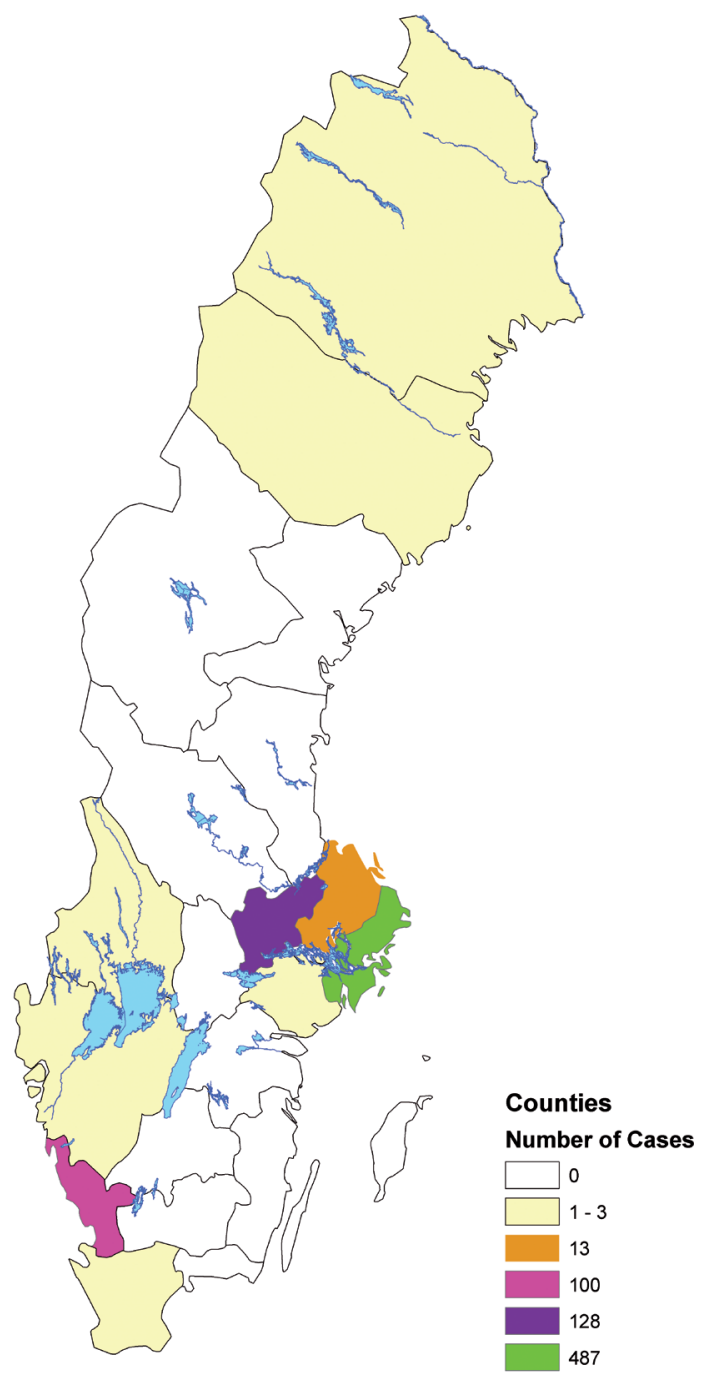

Green: Stockholm County; purple: Västmanland County; pink: Halland County; orange: Uppsala County.

\section{TABLE}

Distribution of genotype for domestic cases with Enterococcus faecium, Sweden, 1 July 2007-28 February $2009(n=738)$

\begin{tabular}{|l|c|c|c|c|}
\hline County & $\begin{array}{c}\text { Number } \\
\text { of cases }\end{array}$ & $\begin{array}{c}\text { E. faecium } \\
\text { vanA }\end{array}$ & $\begin{array}{c}\text { E. faecium } \\
\text { vanB }\end{array}$ & $\begin{array}{c}\text { Incidence } \\
\mathbf{2 0 0 8}^{\mathbf{a}}\end{array}$ \\
\hline Stockholm & 487 & 98 & 387 & 20.9 \\
\hline Västmanland & 128 & 2 & 126 & 33.2 \\
\hline Halland & 100 & - & 100 & 29.3 \\
\hline Other $(\mathrm{n}=7)$ & 23 & - & 21 & $0.06-4.0$ \\
\hline $\begin{array}{l}\text { Total } \\
\text { VRE: vancomyctn-resistant E. faecium and E. faecalis. }\end{array}$ & $\mathbf{7 3 8}$ & $\mathbf{1 0 0}$ & $\mathbf{6 3 4}$ & \\
\hline
\end{tabular}

a Number of domestic VRE cases per 100,000 inhabitants in the year 2008 recently received any medical treatment abroad. A case of VRE is defined as a person with a clinical VRE infection or a person colonised with VRE.

All cases of VRE are mandatorily reported via the national internet-based reporting system SmiNet2 [10]. Case reports are created in this system combining information from the laboratory notification on species and van gene with the clinical notification from the treating physician which contains epidemiological information on country of acquisition, route of transmission and reason for sampling. The descriptive epidemiology of the cases presented in this report is based on data from SmiNet2 covering the period from 1 July 2007 to 28 February 2009. The primary information from the clinical notifications was reviewed and complemented with additional information collected during our investigation in collaboration with the County Departments of Communicable Disease Control, infection control teams and the regional clinical microbiological laboratories.

\section{Identification and susceptibility testing of vancomycin-resistant enterococci}

A preliminary diagnosis of VRE in a clinical sample is based on standard methods for culture, species identification and susceptibility testing. Guidelines for susceptibility testing are provided by the Swedish Reference Group for Antibiotics and are followed by the clinical laboratories [11]. It is recommended that all enterococci are tested for susceptibility to vancomycin and that results are reported back to the clinician for treatment guidance. The preliminary diagnosis of VRE is subsequently verified using genotypic (PCR-based) methods identifying the van genes [12]. Phenotypic detection of vancomycin-resistant $E$. faecium or $E$. faecalis, combined with detection of genetic resistance markers in the isolate constitutes the Swedish case definition for notifiable VRE infections and colonisations.

Contact tracing and screening are done by sampling from faeces and, if applicable, from insertion sites of indwelling catheters and catheter urine, and sometimes also from apparent infection sites on skin and soft tissue. The samples are cultured over night in broth containing vancomycin $4 \mathrm{mg} / \mathrm{L}$ [13], followed by detection through phenotypic or genotypic (PCRbased) methods. Before 2009 some Swedish laboratories used selective broth containing higher vancomycin concentrations $32 \mathrm{mg} / \mathrm{L}$, designed for detection of enterococci with the vanA gene.

During the present investigation, all VRE isolates (with the exception of the majority of isolates from Stockholm County) were submitted to the Swedish Institute for Infectious Disease Control (Smittskyddsinstitutet, SMI) for genetic confirmation of van genes and speciesspecific $d d l$ genes [12]. VRE isolates from Stockholm were investigated using identical methods at the Department of Clinical Microbiology and Infection 
Control, Huddinge, and representative isolates were also analysed at SMI.

\section{Epidemiological typing}

Epidemiological typing was performed using pulsedfield gel electrophoresis (PFGE). Mapping of Smaldigested DNA was performed according to standard procedures for PFGE [14], using the CHEF Mapper XA system (Bio-Rad Laboratories) set at $6 \mathrm{~V} / \mathrm{cm}$. PFGE patterns, comprising bands within the size range 48-400 $\mathrm{kb}$, were analysed and compared using BioNumerics software (version 5.01, Applied Maths). The Dice coefficient was used for pair-wise comparisons of patterns, and the unweighted pair group method with arithmetic mean (UPGMA) for pattern groupings. Position tolerance and optimisation were both set at $1 \%$. PFGE band patterns were defined as identical (100\% pair-wise Dice similarity), closely related (>90\% pair-wise Dice similarity) or unrelated (< $90 \%$ pair-wise Dice similarity).

\section{Results}

During the period from 1 July 2007 to 28 February 2009, a total of 760 VRE cases were reported nationally via SmiNet2 from 13 of 21 Swedish counties, including 493 from Stockholm, 128 from Västmanland and 100 from Halland. The majority of the persons $(n=738,97.1 \%)$ had acquired VRE in Sweden. These 738 domestic cases were notified from 10 counties, and $E$. faecium vanB was the most commonly reported strain $(n=634$, 85.9\%). (Figure 1 and Table).

Of the $634 E$. faecium vanB cases reported, 610 (96\%) were healthcare-related. The epidemic curve for these
610 healthcare-related cases is shown in Figure 2. Spread of E. faecium vanB was reported in several hospitals in the affected counties as well as homes for the elderly. The mean age of the 610 domestic healthcarerelated cases with $E$. faecium vanB was 72 years for females (range $1-98$ years, $n=291$ ) and 68 years for males (range $22-96$ years, $n=319$ ).

\section{Reason for sampling and site of isolation}

Of the 610 healthcare-related domestic $E$. faecium vanB cases reported, 52 (8.5\%), had clinical infections and 494 were colonised. Of these $494,410(67 \%)$ were identified through contact tracing and 84 (14\%) through screening. In $64(10.5 \%)$ of the 610 cases there were miscellaneous, or unknown, reasons for sampling.

According to the first laboratory notifications for each case, the majority of VRE ( $85 \%$ ) were isolated from faecal samples, and $5 \%$ each from wound and urine samples. The remaining $5 \%$ were collected from various other sampling sites. Blood-stream infections caused by VRE were reported for 15 cases during the period from 1 July 2007 to 28 February 2009.

\section{Clonal dissemination of $E$. faecium vanB}

All examined isolates $(n=226)$ of $E$. faecium vanB from the counties of Västmanland and Halland and $93 \%$ of the isolates from Stockholm County gathered during the study period, had identical or closely related PFGE patterns indicating a clonal dissemination (Figure 3). Ten isolates of this $E$. faecium vanB were identified as the cause of invasive bloodstream infections. The isolates had a MIC of vancomycin ranging from $4 \mathrm{mg} / \mathrm{L}$ to

\section{FIGURE 2}

Domestic healthcare-related cases with E. faecium vanB, Sweden, 1 July 2007-28 February 2009 (n=610)

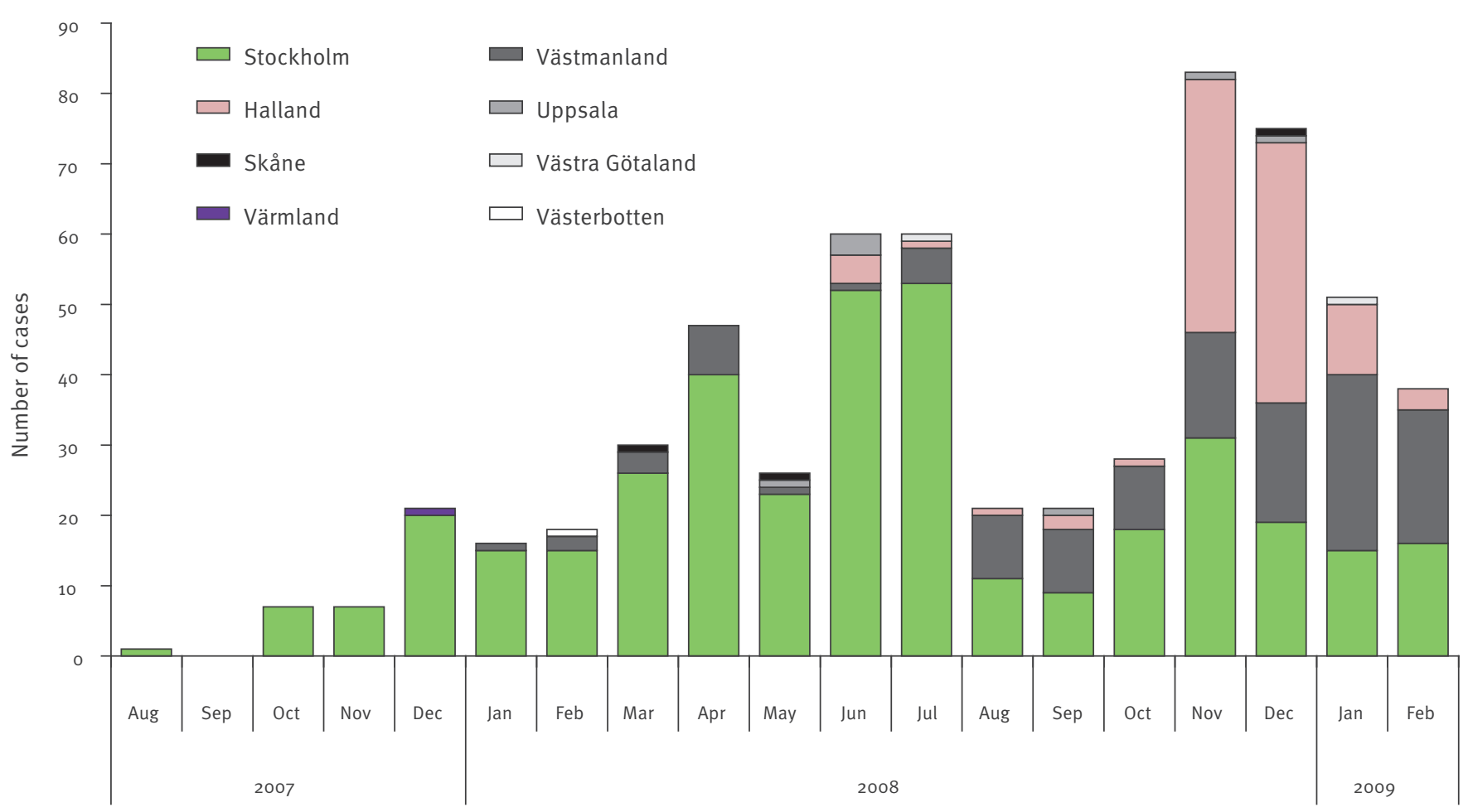


$>128 \mathrm{mg} / \mathrm{L}$ (median value: $32 \mathrm{mg} / \mathrm{L}$, with $80 \%$ of the isolates in the range $16-64 \mathrm{mg} / \mathrm{L}$ ) and a median MIC for teichoplanin of $0.125 \mathrm{mg} / \mathrm{L}$ (range: $0.064-0.25 \mathrm{mg} / \mathrm{L}$ ). The isolates were resistant to ampicillin, ciprofloxacin and macrolides and exhibited low-level resistance to gentamicin. Susceptibility testing for linezolid, tigecycline, daptomycin and quinupristin/dalfopristin was performed on a few of the isolates. However, resistance to linezolid and tigecycline was never recorded, while varying susceptibility profiles were recorded for the other two compounds.

\section{Discussion and conclusion}

Our report describes a current strong increase in mandatorily reported cases of VRE in healthcare facilities in three geographically separate regions of Sweden, i.e. the counties of Stockholm, Västmanland and Halland. This increase was largely characterised by clonal dissemination of an $E$. faecium vanB strain as revealed by contact tracing and screening performed in connection with VRE infections detected in healthcare facilities in these counties. The cause of the dissemination is unknown, and no major changes in the general hospital infection control policies such as changes of nurses per bed ratios or antibiotic policies had been introduced that could explain the increased VRE prevalence.

The three counties accounted for the majority of all domestic cases of VRE reported to the SMI during a period of $\mathbf{2 0}$ months from July 2007 to February 2009.

\section{FIGURE 3}

PFGE patterns of Enterococcus faecium with vanB gene isolated in Sweden, 1 July 2007-28 February 2009

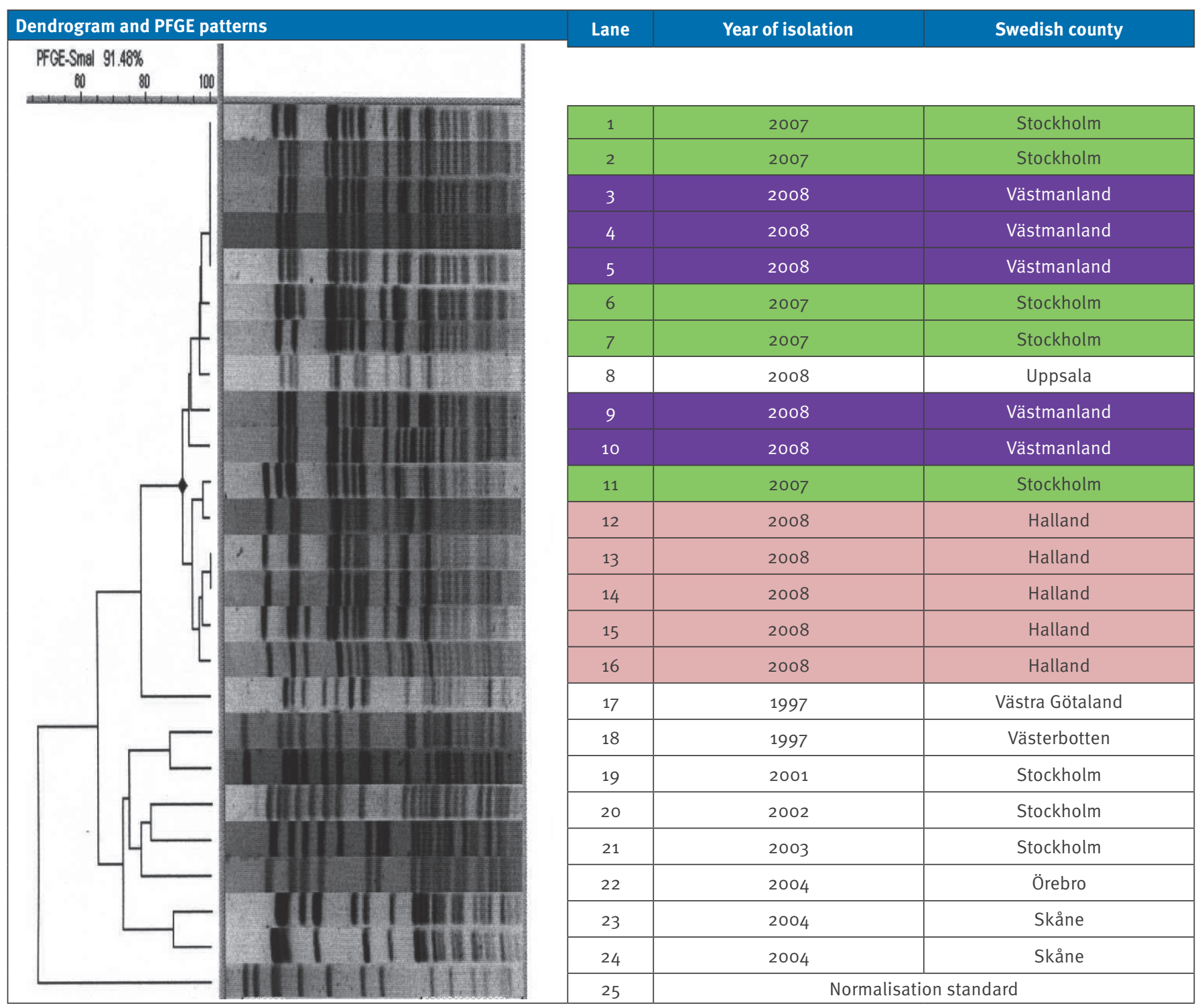

PFGE: pulsed-field gel electrophoresis.

Lanes 1-16 show the closely related band patterns ( $91.5 \%$ pair-wise Dice similarity as indicated by $\diamond$ in the dendrogram) of representative isolates of the current E. faecium vanB strain from Stockholm County (green), Västmanland County (purple) and Halland County (pink), including one isolate from Uppsala County. Lanes 17-24 show band patterns of representative isolates from various minor healthcare-related disseminations of vancomycin-resistant enterococci in Sweden 1997-2004. In lane 25 is the normalisation standard from Staphylococcus aureus NCTC 8325 . 
Despite the marked geographical separation between these counties, the E. faecium vanB isolates were apparently genetically closely related according to the typing results of the isolates. The PFGE pattern of the current strain is seemingly new and has not been seen previously among vancomycin-resistant $E$. faecium isolates in Sweden. Moreover, when compared to PFGE-patterns of a large collection of VRE isolates in Germany, a pattern corresponding to that of this Swedish strain could not be identified (G Werner, personal communication, 2009). Investigations to find possible links to vancomycin-susceptible E. faecium isolates are ongoing, including MLST-typing, since such connections have been described in other outbreak situations [15].

No apparent epidemiological link between the three major affected counties has been identified. Still, some patient exchange does take place between the involved counties, hence a possible epidemiological link involving patients whose VRE-positive status was undetected cannot be excluded.

More than $80 \%$ of the healthcare-associated cases with E. faecium vanB were identified through contact tracing or screening, and only $9 \%$ had a clinical infection. This proportion of clinical infections versus colonisations is in accordance with that reported in a previous outbreak report in Finland [15]. During the study period, 15 of our patients were reported to have a bloodstream infection caused by VRE, ten of which had E. faecium vanB. This compares to a total of 19 bloodstream infections caused by VRE notified in SmiNet2 during the entire period from 2000 to 2006.

The methods used for microbiological processing of the samples obtained from contact tracing and screening for VRE were optimised during the study period (unpublished data). The reference methodology previously endorsed in Sweden, published by the Swedish Society of Medicine and SMI [16], was designed for the selective isolation and identification of the vanA phenotype and therefore included an enrichment broth containing $32 \mathrm{mg} / \mathrm{L}$ of vancomycin. Since MICs of vancomycin for the present $E$. faecium vanB isolates ranged between 4 $\mathrm{mg} / \mathrm{L}$ and $>128 \mathrm{mg} / \mathrm{L}$, laboratories using this methodology for VRE screening might have failed to detect some of the strains belonging to the currently spreading $\operatorname{van} B$ strain, especially in samples with low numbers of VRE. However, as the majority of the isolates (approximately $80 \%$ ) had MICs ranging between $16 \mathrm{mg} / \mathrm{L}$ and $64 \mathrm{mg} / \mathrm{L}$, it is most likely that only few isolates remained undetected due to an unsuitably high vancomycin concentration. Low sensitivity of the laboratory screening method may, however, contribute to the maintenance of undetected dissemination of moderately resistant strains. As a consequence, all Swedish microbiological laboratories have been advised since January 2009 to decrease the vancomycin concentrations in the enrichment broth to $4 \mathrm{mg} / \mathrm{L}$.
The present situation regarding healthcare-associated dissemination of VRE urged the SMI, the Swedish Strategic Programme against antibiotic resistance (Strama) and the National Board of Health and Welfare (NBHW) to initiate a working group with representatives from the County Departments of Communicable Disease Control, infection control teams, and the regional clinical microbiological laboratories in the spring of 2008. The group organised a workshop in December 2008, in which also the National Veterinary Institute participated. They discussed the countermeasures taken so far as well as additional steps needed to stop the spreading of VRE in Swedish healthcare facilities. The workshop was followed by a national one-day educational VRE conference arranged by the SMI. In December 2008, the NBHW commissioned their Central Field Epidemiology Group (CFG) to review the outbreaks, to map the VRE-screening capacities of the microbiological laboratories during an outbreak situation and to suggest actions in order to improve the national coordination of actions to be taken in order to contain the ongoing dissemination of VRE. The report of the CFG formed the basis for a national action plan which is in preparation.

Experiences from the affected healthcare facilities demonstrated that VRE may be found at scattered places in the environment of the wards. It has also proved important to meticulously follow the local cleaning instructions to eradicate VRE from the environment. Intense educational efforts have been taken to persuade the ward personal to follow the basic infection control practices stated by Swedish law [17]. In addition, local educational efforts to increase awareness of hygiene among patients and hospital visitors have been made. Food buffets in the affected hospitals have been removed, and probiotic treatment using yoghurt supplemented with Lactobacillus rhamnosus, has been offered to patients in affected wards [18].

This report describes the, to date, largest known dissemination of VRE in healthcare settings in Sweden. Although occurring in geographically separate counties, the bacteria share the same PFGE pattern indicating a clonal origin. Vigorous counter measures were taken in order to prevent further local and national spreading of these bacteria. Owing to these measures the rate of new cases decreased substantially, but new cases carrying the $E$. faecium vanB strain were still detected.

\section{References}

1. Courvalin P. Vancomycin resistance in gram-positive cocci. Clin Infect Dis. 2006; 42 Suppl. 1:25-34.

2. Boyd DA, Willey BM, Fawcett D, Gillani N, Mulvey MR Molecular characterization of Enterococcus faecalis No60364 with low level vancomycin resistance harbouring a novel D-Ala-D-Ser cluster, vanL. Antimicrob Agents Chemother. 2008; 52(7):2667-72

3. Torell E, Cars O, Olsson-Liljequist B, Hoffman BM, Lindbäck J, Burman LG. Near absence of vancomycin-resistant enterococci but high carriage rates of quinolone-resistant ampicillin-resistant enterococci among hospitalized patients and nonhospitalized individuals in Sweden. J Clin Microbiol. 1999;37(11):3509-13. 
4. Olofsson MB, Pörnull KJ, Karnell A, Telander B, Svenungsson B. Fecal carriage of vancomycin-and ampicillin-resistant enterococci observed in Swedish adult patients with diarrhea but not among healthy subjects. Scand J Infect Dis.2001;33(9):659-62.

5. Swedish Institute of Infectious Disease Control (SMI). Vancomycin-resistant Enterococc infection (VRE). Stockholm: SMI. Updated 13 Jul 2010. Available from: http://www. smittskyddsinstitutet.se/in-english/statistics/vancomycinresistant-enterococc-infection-vre/. Swedish.

6. Torell E, Fredlund H, Törnquist E, Myhre EB, Sjöberg L, Sundsfjord A. Intrahospital spread of vancomycin-resistant Enterococcus faecium in Sweden. Scand J Infect Dis. 1997;29(3):259-63.

7. Granlund M, Carlsson C, Edebro H, Emanuelsson K, Lundholm R. Nosocomial outbreak of vanB2 vancomycinresistant Enterococcus faecium in Sweden. J Hosp Infect 2006;62(2):254-6.

8. The European Antimicrobial Resistance Surveillance System (EARSS). Reports and Articles. Bilthoven: Rijksinstituut voor Volksgezondheid en Milieu (RIVM). Available from: http://www. rivm.nl/earss/result/Monitoring_reports/

9. Werner G, Coque TM, Hammerum AM, Hope R, Hryniewicz W, Johnson A, et al. Emergence and spread of vancomycin resistance among enterococci in Europe. Euro Surveill. 2008;13(47):pii=19046. Available from: http://www. eurosurveillance.org/ViewArticle.aspx?Articleld=19046

10. Rolfhamre P, Janson A, Arneborn M, Ekdahl K. SmiNet-2: Description of an internet-based surveillance system for communicable diseases in Sweden. Euro Surveill. 2006;11(5):pii=626. Available from: http://www. eurosurveillance.org/ViewArticle.aspx?Articleld =626

11. The Swedish Reference Group for Antibiotics. Enterococci. Updated 28 April 2009. Available from: http://www.srga.org/ FOTNOT/FOTEFEF.HTM.

12. Dutka-Malen S, Evers S, Courvalin P. Detection of glycopeptide resistance genotypes and identification to the species level of clinically relevant enterococci by PCR. J Clin Microbiol. 1995;33(1):24-7.

13. The Swedish Reference Group for Antibiotics. Multiresistenta bakterier i svensk hälso- och sjukvård - för personal på mikrobiologiska laboratorier. [Multiresistant bacteria in Swedish healthcare - for staff in microbiological laboratories]. Available from: http://www.srga.org/MRB/index-lab.htm. Swedish.

14. Maslow J, Slutsky A, Arbeit R. Application of pulsed-field gel electrophoresis to molecular epidemiology. In: Persing D, Smith T, Tenover F, White T, editors. Diagnostic molecular microbiology: principles and applications. Washington, D.C.: ASM Press; 1993. p. 563-72.

15. Suppola JP, Kolho E, Salmenlinna S, Tarkka E, Vuopio-Varkila J, Vaara M. vanA and vanB incorporate into an endemic ampicillin-resistant vancomycin-sensitive Enterococcus faecium strain: effect on interpretation of clonality. J Clin Microbiol. 1999; 37(12):3934-9.

16. Swedish Institute of Infectious Disease Control (SMI) and Swedish Society of Medicine. Referensmetodik: Bakteriologisk diagnostik av infektioner i hud, mjukdelar, skelett och inre organ. [Reference methodology for diagnostics of infections of the skin, soft tissue, skeleton and inner organs]. In: I 11. Referensmetodik för kliniskt mikrobiologiska laboratorier. [Reference methodology for clinical microbiological laboratories]. Stockholm: SMI; 2003. Available from: http:// referensmetodik.smi.se/w/Bilaga_1:_Substratrecept-_Hud, mjukdelar,_skelett_och_inre_organ. Swedish.

17. Socialstyrelsen. Socialstyrelsens föreskrifter om basal hygien inom hälso- och sjukvården m.m. Stockholm: Socialstyrelsen; December 2007. [Swedish]. Available from: http://www. socialstyrelsen.se/sosfs/2007-19

18. Manley KJ, Fraenkel MB, Mayall BC, Power DA. Probiotic treatment of vancomycin resistant enterococci; a randomised controlled trial. Med J Aust. 2007;186(9):454-7. 